\title{
Post-contrast acute kidney injury - Part 1: Definition, clinical features, incidence, role of contrast medium and risk factors
}

\author{
Recommendations for updated ESUR Contrast Medium Safety Committee guidelines
}

\author{
Aart J. van der Molen ${ }^{1}$ - Peter Reimer ${ }^{2}$ - Ilona A. Dekkers ${ }^{1} \cdot$ Georg Bongartz $^{3}$ - Marie-France Bellin ${ }^{4}$. \\ Michele Bertolotto $^{5}$. Olivier Clement ${ }^{6}$. Gertraud Heinz-Peer ${ }^{7}$. Fulvio Stacul ${ }^{8}$. Judith A. W. Webb ${ }^{9}$. \\ Henrik S. Thomsen ${ }^{10}$
}

Received: 3 October 2017 / Revised: 22 November 2017 / Accepted: 5 December 2017 / Published online: 9 February 2018

(C) The Author(s) 2018. This article is an open access publication

\begin{abstract} recommendations based on it, which were used to prepare the new guidelines, are presented in two papers.

Key Points

- PC-AKI is the preferred term for renal function deterioration after contrast medium.

- PC-AKI has many possible causes.

- The risk of AKI caused by intravascular contrast medium has been overstated.

- Important patient risk factors for PC-AKI are CKD and dehydration.
\end{abstract}

Purpose The Contrast Media Safety Committee (CMSC) of the European Society of Urogenital Radiology (ESUR) has updated its 2011 guidelines on the prevention of post-contrast acute kidney injury (PC-AKI). The results of the literature review and the

Areas covered in part 1 Topics reviewed include the terminology used, the best way to measure eGFR, the definition of PC-AKI, and the risk factors for PC-AKI, including whether the risk with intravenous and intra-arterial contrast medium differs.

Keywords Contrast media $\cdot$ Acute kidney injury $\cdot$ Glomerular filtration rate $\cdot$ Risk factors $\cdot$ Practice guidelines as topic

$\begin{array}{ll}\text { Abbreviations } \\ \text { ACR } & \text { American College of Radiology } \\ \text { ADQI } & \text { Acute Dialysis Quality Initiative } \\ \text { AGREE } & \begin{array}{l}\text { Appraisal of Guidelines for Research and } \\ \text { Evaluation }\end{array} \\ \text { AKI } & \text { Acute kidney injury } \\ \text { AKIN } & \text { Acute Kidney Injury Network } \\ \text { BIS } & \text { Berlin Initiative Study } \\ \text { BUN } & \text { Blood urea nitrogen } \\ \text { CA } & \text { Coronary angiography } \\ \text { CI } & \text { Confidence interval } \\ \text { CI-AKI } & \text { Contrast-induced acute kidney injury } \\ \text { CIN } & \text { Contrast-induced nephropathy } \\ \text { CKD } & \text { Chronic kidney disease } \\ \text { CKD-EPI } & \text { ChronicKidneyDiseaseEpidemiologyCollaboration }\end{array}$

Henrik S. Thomsen

Henrik.Thomsen@regionh.dk

Extended author information available on the last page of the article

$\begin{array}{ll}\text { CM } & \text { Contrast media } \\ \text { CMSC } & \text { Contrast Media Safety Committee } \\ \text { CT } & \text { Computed tomography } \\ \text { eGFR } & \text { Estimated glomerular filtration rate } \\ \text { EBM } & \text { Evidence-based medicine } \\ \text { ERBP } & \text { European Renal Best Practice } \\ \text { ESUR } & \text { European Society of Urogenital Radiology } \\ \text { FAS } & \text { Full age spectrum } \\ \text { GFR } & \text { Glomerular filtration rate } \\ \text { IA } & \text { Intra-arterial } \\ \text { ICU } & \text { Intensive care unit } \\ \text { IDMS } & \text { Isotope Dilution Mass Spectroscopy } \\ \text { IV } & \text { Intravenous } \\ \text { KDIGO } & \text { Kidney Disease Improving Global Outcome } \\ \text { LM } & \text { Lund Malmö } \\ \text { MDRD } & \text { Modification of Diet in Renal Disease } \\ \text { NICE } & \text { National Institute for Health and Care Excellence } \\ \text { OCEBM } & \text { Oxford Center for Evidence Based Medicine } \\ \text { PC-AKI } & \text { Post-contrast acute kidney injury } \\ \text { PCI } & \text { Percutaneous coronary intervention } \\ \text { PICO } & \text { Patient-Intervention-Comparator-Outcome } \\ \end{array}$


PoC Point of Care

PS Propensity Score

RANZCR Royal Australian and New Zealand College of Radiology

RCR Royal College of Radiologists

RCT Randomised controlled trials

RRT Renal replacement therapy

RSTN Radiological Society of The Netherlands

$\mathrm{sCr} \quad$ Serum creatinine

WG Writing Group

\section{Introduction}

The Contrast Media Safety Committee (CMSC) of the European Society of Urogenital Radiology (ESUR) produced their most recent guidelines on what was then termed contrast induced nephropathy (CIN) in 2011 [1]. Guidelines on the use of contrast media (CM) in patients on dialysis and the use of $\mathrm{CM}$ in diabetic patients using metformin were published in 2002 and 2014 [2, 3]. This review provides the information to support the new CMSC guidelines, which were obtained using a structured literature review based on clinical questions and patient-intervention-comparator outcome (PICO) formatting. Since the literature related to the topics considered is so large, the results of the review have been split into two papers. The review only considers post-contrast kidney injury (PC$\mathrm{AKI}$ ) after intravascular iodine-based CM. Acute kidney injury (AKI) is not associated with intravascular gadoliniumbased contrast agents in doses approved for clinical magnetic resonance imaging.

In this first paper on PC-AKI, the following topics related to diagnosis and risk are considered:

1. The clinical features and incidence of PC-AKI.

2. The choice of terms for renal function deterioration after $\mathrm{CM}$, the degree of renal function deterioration used to diagnose PC-AKI, and the definitions of intravenous and intra-arterial $\mathrm{CM}$ administration.

3. The reliability of the various equations used to measure eGFR and the appropriate timing of eGFR measurement before CM administration.

4. The evidence that CM can cause AKI, the levels of renal function at which there is a risk of PC-AKI, and the recent evidence suggesting that the risk of PC-AKI may be lower after intravenous than after intra-arterial contrast medium.

5. The importance of the many risk factors for PC-AKI described in the literature.

Recommendations are made for items $2-5$. The recommendations have been incorporated into version 10 of the ESUR CMSC guidelines (see Table 4 in Part 2).

\section{Clinical features and incidence of PC-AKI}

The term PC-AKI is used to describe a decrease in renal function that follows intravascular administration of CM. The decrease in renal function is usually mild, peaking at 2-3 days, and renal function usually returns to baseline values within 13 weeks. Like all forms of AKI, an episode of PC-AKI is a marker for increased short- and long-term morbidity and mortality and prolonged hospital stay [4-10].

The risk of PC-AKI after intravenous (IV) CM has probably been overestimated. Two meta-analyses of 19,000 patients who had received IV CM showed PC-AKI incidences of 6.4 $\%(95 \%$ CI 5.0-8.1) and 5.0 \% (95\% CI 3.8-6.5) [11, 12]. In $1 \%$ of all patients the decline in renal function persisted for 2 months, but the weighted incidence of renal replacement therapy (RRT) was as low as $0.06 \%$ [11].

It has been suggested that intra-arterial (IA) CM administration during catheter-based angiography, with or without percutaneous coronary intervention (PCI), is associated with a higher incidence of PC-AKI than IV CM administration [13, 14]. However, there are many causes of AKI following angiography, and AKI may wrongly be attributed to the CM [15]. Catheter-based procedures may be complicated by haemodynamic instability, and by embolization of cholesterol or thrombi to the renal arteries caused by catheter manipulations [16]. Any of these may lead to post-interventional AKI, which is often misinterpreted as contrast-induced acute kidney injury (CI-AKI) [17, 18]. A large meta-analysis of cardiovascular outcomes after coronary angiography (CA) showed that the association between PC-AKI and mortality was strongly confounded by baseline clinical features that predisposed to both kidney injury and mortality [6]. The risk of PC-AKI reported in studies adjusted for confounding features was much lower than that from unadjusted studies. The incidence of AKI was $2.3 \%$ and need for RRT $0.3 \%$ in a recent retrospective analysis using propensity matching with controls of over 2,000 patients who had PCI [7].

\section{Materials and methods}

The guidelines were developed using the Appraisal of Guidelines for Research and Evaluation (AGREE) II document [19]. A guideline Writing Group (WG) prepared ten clinical questions in Patient - Intervention - Comparison Outcome (PICO) format [20]. Systematic search strings were developed with a professional librarian for four different biomedical literature databases (PubMed, Web of Science, Embase, and the Cochrane Library). Language was limited to English and German. Where necessary, additional systematic searches on specific topics, such as pediatric PC-AKI, were performed. 
The titles and abstracts were screened for relevance and selected on predefined in- and exclusion criteria. Emphasis was put on comparative studies with strong scientific evidence, such as meta-analyses and systematic reviews, and prospective randomized controlled trials (RCTs). In addition, evidence was collected from comparative cohort, patient-control and noncomparative studies. Other important quality criteria were size of population studied, duration of follow-up and control for bias. Cross-referencing was used to find additional data. The four systematic searches for paper 1 yielded 3,086 references, of which 705 were selected from their title and abstract. The full texts of these 705 publications were reviewed and 105 were selected for inclusion in this paper. The quality of evidence was evaluated according to the Oxford Centre for Evidence Based Medicine (OCEBM) 2011 levels of evidence: Grade A: established scientific evidence; Grade B: scientific presumption; Grade C: low level of evidence [21]. Where there was no scientific evidence, recommendations were based on WG consensus and graded as expert opinion (Grade D).

Other factors such as availability of techniques or expertise, organizational consequences, financial costs and patient preferences were also considered. CM manuals and guidelines (American College of Radiology (ACR), Royal Australian and New Zealand College of Radiology (RANZCR), National Institute for Health and Care Excellence (NICE), Royal College of Radiologists (RCR), and Radiological Society of the Netherlands (RSTN)) were consulted where appropriate.

The recommendations prepared by the WG are the result of the available scientific evidence combined with these other sources of information. They were discussed at the CMSC meeting in Copenhagen, Denmark in February 2017 and the text of the final recommendations and guidelines was subsequently approved by the academic members of the CMSC. Once published in print, the validity of the CMSC guidelines will be routinely set at 6 years. However, the CMSC members constantly monitor the validity of the guidelines, and can propose revision at an earlier date if deemed necessary.

\section{Results}

\section{QUESTION 1: What are the preferred terms and definitions to be used in PC-AKI?}

\section{Terminology}

Until recently there has not been a generally accepted term for acute renal failure, which is a complex disorder with many possible causes and risk factors. Several nephrology groups, such as the Acute Dialysis Quality Initiative (ADQI) [22] and Kidney Disease: Improving Global Outcome (KDIGO) [23], have worked on finding a suitable term. The Acute Kidney Injury Network (AKIN), a group of experts in Critical Care and Nephrology, suggested Acute Kidney Injury (AKI) as the preferred term for acute renal failure to be used for all forms of AKI [24].

The CMSC recommends that the term PC-AKI should replace the older term of contrast-induced nephropathy $(\mathrm{CIN})$ and suggests using the terms recommended by the ACR Committee on Drugs and Contrast Media [25] when AKI follows CM administration (Table 1). They state that post-contrast acute kidney injury (PC-AKI) is a general term that should be used if there is a sudden deterioration in renal function within $48 \mathrm{~h}$ of the intravascular administration of iodine-based CM. They describe PC-AKI as a correlative diagnosis. They recommend that the term contrast-induced acute kidney injury (CI-AKI) is reserved for cases where a causal relation can be shown between the administered CM and the deterioration in renal function. However, in clinical practice it is usually difficult to distinguish CI-AKI from PC-AKI and very few of the published studies have a suitable control group to allow the two conditions to be separated. Thus, many cases of PC-AKI seen in clinical practice or reported in clinical studies are likely to be coincident to, but not caused by, CM administration.

\section{Renal function definitions of PC-AKI}

The diagnosis of PC-AKI is usually based on surrogate measures of absolute or relative change in serum creatinine $(\mathrm{sCr})$, rather than patient outcomes, such as renal failure, need for RRT or mortality. The KDIGO Practice Guidelines [26, 27] adopted the older AKIN criteria [24] and recommended division of AKI into three stages dependent on $\mathrm{sCr}$ and/or urine output (Table 2).

The ESUR CMSC defined Contrast-Induced Nephropathy $(\mathrm{CIN})$ in their first survey-based guideline as "a condition in which an impairment in renal function (an increase in $\mathrm{sCr}$ by more than $25 \%$ or $44 \mu \mathrm{mol} / \mathrm{L}$, or $0.5 \mathrm{mg} / \mathrm{dl}$ ) occurs within 3 days following the intravascular administration of a contrast medium in the absence of an alternative aetiology" [28].

Multiple studies have shown that the incidence of PC-AKI is largely dependent on the definition used [29-31]. A relative increase in $\mathrm{sCr}$ of $>25 \%$ has been the most sensitive indicator, with absolute values being less sensitive. In coronary angiography studies, relative definitions had more prognostic

Table 1 PC-AKI: Terminology and definition

The preferred term for acute kidney injury associated with CM administration when no control population is available is Post-Contrast Acute Kidney Injury (PC-AKI). The term Contrast-Induced Acute Kidney Injury (CI-AKI) should be used only when comparison with a control allows CM to be shown to be the cause of the acute kidney injury.

Level of Evidence D

PC-AKI and CI-AKI should be defined as an increase in $\mathrm{sCr}$ of $\geq$ $0.3 \mathrm{mg} / \mathrm{dl}$, or of $\geq 1.5-1.9$ times baseline (KDIGO definition of AKI) in the 48-72 $\mathrm{h}$ following CM administration.

Level of Evidence C 
Table 2 Acute Kidney Injury Staging (KDIGO) and CKD-EPI and Schwartz Equations for calculating eGFR

(a) KDIGO staging for AKI

Stage

1

2

3
Serum creatinine

$\mathrm{sCr} \geq 0.3 \mathrm{mg} / \mathrm{dl}(\geq 26.5 \mu \mathrm{mol} / \mathrm{L})$, or

$\mathrm{sCr}$ increase of $1.5-1.9 \mathrm{x}$ baseline

sCr increase of 2.0-2.9 $\mathrm{x}$ baseline

$\mathrm{sCr} \geq 4.0 \mathrm{mg} / \mathrm{dl}(\geq 354 \mu \mathrm{mol} / \mathrm{L})$ or

$\mathrm{sCr}$ increase $\geq 3.0 \mathrm{x}$ baseline

or need for renal replacement therapy
Urine output

$<0.5 \mathrm{ml} / \mathrm{kg} / \mathrm{h}$ for $6-12 \mathrm{~h}$

$<0.5 \mathrm{ml} / \mathrm{kg} / \mathrm{h}$ for $\geq 12 \mathrm{~h}$

$<0.3 \mathrm{ml} / \mathrm{kg} / \mathrm{h}$ for $\geq 24 \mathrm{~h}$

or Anuria for $\geq 12 \mathrm{~h}$

(b) $\mathrm{CKD}$-EPI equation ( $\mathrm{sCr}$ in $\mu \mathrm{mol} / \mathrm{L}$; age in years).

$\operatorname{eGFR}\left(\mathrm{ml} / \mathrm{min} / 1.73 \mathrm{~m}^{2}\right)=$

Female $\mathrm{sCr} \leq 62 \mu \mathrm{mol} / \mathrm{L}$ :

Female $\mathrm{sCr}>62 \mu \mathrm{mol} / \mathrm{L}$ :

Male $\mathrm{sCr} \leq 80 \mu \mathrm{mol} / \mathrm{L}$ :

Male $\mathrm{sCr}>80 \mu \mathrm{mol} / \mathrm{L}$ :

All equations x 1.159 if African American race

$144 \times(\mathrm{sCr} / 62)^{-0.329} \times 0.993^{\text {Age }}$
$144 \times(\mathrm{sCr} / 62)^{-1.209} \times 0.993^{\text {Age }}$
$141 \times(\mathrm{sCr} / 80)^{-0.411} \times 0.993^{\text {Age }}$
$141 \times(\mathrm{sCr} / 80)^{-1.209} \times 0.993^{\text {Age }}$

(c) Revised Schwartz equation ( $\mathrm{sCr}$ in $\mu \mathrm{mol} / \mathrm{L}$; patient length in $\mathrm{cm}$ ).

relevance [29]. In other studies, however, relative increases in $\mathrm{sCr}$ were found to overestimate PC-AKI and absolute values were considered preferable [32]. Relative values seem to be more sensitive for patients with CKD 3B (eGFR 30-44 ml/ $\mathrm{min} / 1.73 \mathrm{~m}^{2}$ ) and CKD 2 (eGFR $60-89 \mathrm{ml} / \mathrm{min} / / 1.73 \mathrm{~m}^{2}$ ), and absolute values seem to be more sensitive for patients with CKD 3A (eGFR 45-59 ml/min/1.73 $\mathrm{m}^{2}$ ) [33, 34]. Studies in critically ill populations using the AKIN definition found that development of AKI correlated with ICU mortality [35].

The KDIGO criteria are more rigorously derived than the CIN definition and are now being adopted as the standard for PC-AKI studies [36]. The CMSC, like the European Renal Best Practice (ERBP) working group, recommends that the definition of PC- AKI (or CI-AKI) should use the KDIGO definition of AKI: an increase in $\mathrm{sCr}$ of $\geq 0.3 \mathrm{mg} / \mathrm{dl}$, or a $\mathrm{sCr}$ increase of $\geq 1.5-1.9$ times baseline [37, 38] (Table 1). The KDIGO recommendation is that the renal function change should be within $48 \mathrm{~h}$, but the CMSC recommends retaining a period of $48-72 \mathrm{~h}$ after $\mathrm{CM}$ as being more practical for diagnosing PC-AKI in radiological practice, the majority of which involves outpatients.

\section{Intravenous and direct and indirect intra-arterial CM administration: definition of terms}

The term intravenous CM administration indicates that CM reaches the renal arteries after dilution by circulation through the right heart and pulmonary circulation or a systemic capillary bed.

The same is true for intra-arterial CM administration with second-pass renal exposure, such as via catheters into the right heart and pulmonary arteries and via catheters directly in the carotid, subclavian, brachial, coronary and mesenteric arteries, as well as into the infrarenal aorta and the iliac, femoral and crural arteries. Note: Because of backflow during this type of IA injection, small doses of CM may reach the kidney in a relatively undiluted form.

The term intra-arterial CM administration with first-pass renal exposure indicates that $\mathrm{CM}$ reaches the renal arteries during its first pass in a relatively undiluted form, depending on the distance of the site of injection from the renal arteries. This occurs with injections through catheters into the left heart, the thoracic and suprarenal abdominal aorta, and selectively into the renal arteries. Note: In suprarenal aortic injections, some of the injected CM escapes via suprarenal aortic side-branches and reaches the kidney after dilution in the circulation.

\section{QUESTION 2: What are the best equations for GFR estimation in European populations?}

Total glomerular filtration rate (GFR) is considered the best overall index of kidney function, but cannot be measured easily in clinical practice, so GFR is estimated using $\mathrm{sCr}$ as an endogenous filtration marker. In 1999, the Modification of Diet in Renal Disease (MDRD) equation [39] was introduced for estimating GFR. The quality of GFR estimates largely depends on the accuracy of the creatinine measurements, and should be based on $\mathrm{sCr}$ assays standardized to reference methods [40]. The MDRD equation has therefore been reexpressed for use with $\mathrm{sCr}$ assays standardized using isotope dilution mass spectroscopy (IDMS) [41]. 
In 2009, the CKD-EPI equation was proposed by the Chronic Kidney Disease Epidemiology Collaboration (CKD-EPI), and was shown to be superior to the MDRD equation, especially at higher GFRs (Table 2) [42]. The National Kidney Foundation recommended replacing the MDRD by the CKD-EPI equation for routine clinical use [43]. The CMSC therefore recommends the CKD-EPI equation for routine use in adults (Table 3). All creatinine-based equations should be used with caution in people with abnormally high or low muscle mass. Caution should also be exercised in patients with AKI, because sCr takes several days to stabilize and may not reflect current GFR.

There are other equations for specific subgroups, such as the Lund-Malmö (LM) revised equation for the Swedish population [44], the Berlin Initiative Study (BIS-1) equation for the elderly German population [45], and the full age spectrum (FAS) equation for children and adults [46]. However, these equations have not been validated in other populations. Cystatin $\mathrm{C}$ equations for estimation of GFR may have advantages over sCr-based equations but are limited by additional costs and lack of an international reference system for calibration [47].

\section{Estimation of GFR in children}

When estimating GFR in children, $\mathrm{sCr}$ levels should be measured by standardized reference methods because serum concentrations are lower than in adults [48]. The CMSC therefore recommends the revised Schwartz equation for routine clinical use in children (Table 3). The widely-used Schwartz equation

Table 3 Formulae for eGFR and timing of eGFR measurement

The CKD-EPI equation for estimated GFR (eGFR) is recommended for adults. As with all creatinine-based eGFRs, results should be interpreted with caution in people with abnormally high or low muscle mass

Level of Evidence A

The revised Schwartz formula (2009) for eGFR is recommended for children. As with all creatinine-based eGFRs, results should be interpreted with caution in people with abnormally high or low muscle mass

Level of Evidence $\mathrm{C}$

eGFR is not reliable in patients with known AKI

Level of Evidence A

The CMSC considers eGFR measurements before intravascular $\mathrm{CM}$ exposure valid for a maximum of:

1) 7 days* if the patient has (a) an acute disease, an acute deterioration of a known chronic disease or any other adverse event that could have negatively influenced renal function (eGFR), or (b) is a hospital inpatient

2) 3 months (a) if the patient has a chronic disease with stable renal function (eGFR) and (b) in all other patients

Level of Evidence D

*Note: in patients with AKI it is advisable to monitor eGFR frequently, so a maximum of 1-2 days may be advisable.
[49] was revised in 2009 to include the IDMS method and plasma iohexol clearance as standardized reference methods [50] (Tables 2 and 3).

A Cystatin C-based equation has been proposed that showed the best accuracy (91\%) when combined with height/SCr, height, sex and blood urea nitrogen (BUN) [49]. However, this requires an additional BUN, which lacks standardized measurement, and Cystatin $\mathrm{C}$ requires standardization and calibration [51]. In children with increased muscle mass both the $\mathrm{sCr}$ and Cystatin $\mathrm{C}$ based Schwartz formulas tend to overestimate GFR.

\section{Point-of-care creatinine measurements}

Point-of-care (PoC) whole blood creatinine may be measured with the older Jaffe (alkaline picrate) method or by enzymatic methods, with the latter considered more accurate. Although such measurements have practical advantages in patients with increased risk of PC-AKI, PoC devices may lead to overestimation of renal function in severe kidney failure with resultant incorrect risk stratification [52]. Laboratory professionals should be consulted about analytical performance and quality assurance of whole blood PoC creatinine measurement.

\section{For how long do GFR estimations remain valid?}

There are no studies available on how long eGFR measurements remain valid for estimating the PC-AKI risk. The eGFR measurements can be regarded as stable in individuals without CKD or underlying co-morbidities such as heart failure or hypertension who are not taking nephrotoxic drugs.

The CMSC considers eGFR measurements before intravascular CM exposure valid for a maximum of:

\section{(1) 7 days* if the patient}

a) has an acute disease, an acute deterioration of a known chronic disease or any other adverse event that could have negatively influenced renal function (eGFR), or

b) is a hospital inpatient

(2) 3 months

a) if the patient has a chronic disease with stable renal function (eGFR), and

b) in all other patients (Table 3)

*Note: In patients with AKI, eGFR should be monitored frequently, and a maximum of 1-2 days is advisable. 


\section{QUESTION 3: What is the evidence that contrast media are truly a causative factor in AKI and what are the eGFR values below which there is a risk of PC-AKI?}

Contrast-induced nephropathy was accepted for many years, but more recently it has been questioned whether $\mathrm{CM}$ causes the deterioration in renal function that may occur after $\mathrm{CM}$ administration [17, 53]. There are important limitations in many studies that assess whether CM causes AKI. Most studies evaluate the use of IA CM in CA and/or percutaneous coronary intervention (PCI) in patients with significant comorbidities and therefore may not be relevant for intravenous administration, and most studies do not have adequate control groups [54, 55].

\section{Intravenous $\mathrm{CM}$ administration}

There is controversy about the causal relationship between exposure to IV CM and PC-AKI, since there are no prospective RCTs confirming this association [56, 57]. Without controlled studies, many factors such as diet, hydration, physiological variation in $\mathrm{sCr}$ over time, and a variety of nephrotoxic risk factors, including medications, which may influence renal function, cannot be distinguished from any effect of the CM [17, 18, 58]. Although RCTs have the strongest research design for assessing the effects of interventions, assessment of rare conditions such as PC-AKI by RCT would require large numbers of patients [53].

Based on comparisons of the relatively few studies with and without control populations it has been suggested that the risk of PC-AKI after IV CM has been overestimated [53, 59]. A meta-analysis that retrospectively studied 13 non-randomised controlled studies was unable to find an increased incidence of AKI in patients who received intravenous contrast medium [60].

Evidence from observational studies may need to be used, despite the recognised methodological problems [61]. Recently, a few large-scale studies using propensity score (PS)-matching for the evaluation of PC-AKI in patients undergoing contrast-enhanced $\mathrm{CT}$, which stratified subjects according to their baseline $\mathrm{sCr}$ or eGFR, have been published [62-65]. These studies were unable to identify a risk of PC-AKI in patients with eGFR $\geq 30$ $\mathrm{ml} / \mathrm{min} / 1.73 \mathrm{~m}^{2}$, but there is conflicting evidence on whether patients with severe renal impairment (eGFR $<30 \mathrm{ml} / \mathrm{min} / 1.73 \mathrm{~m}^{2}$ ) are at increased risk of PC-AKI $[63,65]$. Lack of information on hydration status was a limitation in these studies, but when hydration status was added to an improved PS model, the findings were similar [66]. The failure to adjust for the various predictor variables in previous observational studies may explain the differences between them and the recent PS matching- based studies. Remaining major limitations of observational studies are the low numbers of patients with severe renal impairment, and the variability of data available on, for example, prophylactic volume expansion and the CM dose administered.

\section{Comparison of intra-arterial and intravenous CM administration in the same patients}

A limited number of studies have directly compared IV to IA $\mathrm{CM}$ administration, using the patient as their own control. The risk of PC-AKI as well as its clinical course was independent of the route of administration in four retrospective studies of patient populations with varying degrees of renal impairment [67-70], and PC-AKI rates were similar to the rates for unenhanced CT [70]. However, these studies suffer from selection bias and procedures with IA CM administration with first- and second-pass renal exposure were not separated.

\section{Intra-arterial CM administration}

The PC-AKI incidence following direct IA CM administration with first-pass renal exposure is frequently reported to be higher than after IV administration, but this remains controversial $[71,72]$. Problems with confounding factors are most significant in studies on patients that undergo catheter-based CA and/or PCI because it is impossible to separate the effects of contrast media from the effects of co-morbidity, catheter manipulations or other procedural variables. In large metaanalyses on cardiovascular outcome the PC-AKI incidence may have been strongly confounded by baseline clinical characteristics, both for first- and second-pass IA $\mathrm{CM}$ administration [6,73]. Nonetheless, AKI in general is a significant problem in these patients and is associated with increased morbidity, longer length of hospital stay and higher cost [74], and may be associated with mortality in a significant percentage of cardiac patients [7]. Second-pass IA CM administration is considered to have no higher risk than IV CM administration.

Since it is difficult to separate the effects of the procedure from those of the CM, the CMSC decided, for optimal safety, to choose a higher cut-off eGFR level for preventive measures in patients undergoing catheterbased diagnostic or interventional examinations using IA $\mathrm{CM}$ administration with first-pass renal exposure, even though some of the risk may relate to the procedure. Also, the CMSC decided to include CA and/or PCI in this category because these examinations frequently combine IA CM administration with both first- and second-pass renal exposure (Table 4). 
Table 4 Risk of PC-AKI

(a) Levels of eGFR at which there is a risk

The risk of PC-AKI in patients with eGFR $\geq 30 \mathrm{ml} / \mathrm{min} / 1.73 \mathrm{~m}^{2}$ after intravenous and intra-arterial CM administration with second-pass renal exposure is very low, but there is conflicting evidence on the risk for intra-arterial $\mathrm{CM}$ administration with first-pass renal exposure

Level of Evidence: B

Preventive measures are recommended for patients with eGFR $<30$ $\mathrm{ml} / \mathrm{min} / 1.73 \mathrm{~m}^{2}$ before intravenous and intra-arterial CM administration with second-pass renal exposure

Level of Evidence: C

Preventive measures are recommended for patients with eGFR $<45$ $\mathrm{ml} / \mathrm{min} / 1.73 \mathrm{~m}^{2}$ if they are in ICU or if they will receive intra-arterial $\mathrm{CM}$ administration with first-pass renal exposure

Level of Evidence: $\mathrm{C}$

Recommendations for prevention of PC-AKI in adults may also be used in children and adolescents

Level of Evidence D

(b) Risk factors

The principal risk factor for PC-AKI is impaired renal function. Most other published patient-related risk factors are risk factors for the presence of chronic kidney disease or AKI, and are not specific for PC-AKI

Level of Evidence B

There is no difference in PC-AKI risk between IOCM and LOCM. The use of ionic, high-osmolar $\mathrm{CM}$ and repeated $\mathrm{CM}$ injections in a short period (48-72 h) should be avoided

Level of Evidence C

When $\mathrm{CM}$ are injected intravenously, there is insufficient evidence that $\mathrm{CM}$ dose is a risk factor. When $\mathrm{CM}$ are injected intra-arterially, the ratio of CM dose (in gram Iodine) / absolute eGFR (in $\mathrm{ml} / \mathrm{min}$ ) should be kept below 1.1 or the ratio of CM volume (in ml) / eGFR (in $\mathrm{ml} / \mathrm{min} / 1.73 \mathrm{~m}^{2}$ ) should be kept below 3.0 when using a CM concentration of $350 \mathrm{mgl} / \mathrm{ml}$

Level of Evidence C

\section{Special populations}

There is limited evidence about PC-AKI in several special populations, such as patients with renal or renal and pancreatic transplants, or critically ill patients. In renal transplant recipients, the incidence of PC-AKI in patients receiving either IV or IA CM was not higher than in patients without transplants, and there was no graft loss or need for dialysis [75-77]. Critically ill patients in ICU with multi-organ disease have a greater risk profile for AKI than other inpatients, and AKI incidence varies with subpopulation, study design and hydration status $[33,78,79]$. Without properly controlled studies, it is impossible to know the role of CM in causing the AKI. Although earlier studies failed to show a role of CM [80, 81], a recent large PS-matched controlled study suggested an increased PC-AKI risk for ICU patients with eGFR $<45 \mathrm{ml} /$ $\min / 1.73 \mathrm{~m}^{2}$ [82].

\section{Paediatric PC-AKI}

There are very few studies on paediatric PC-AKI [83-85]. As the incidence of PC-AKI seems similar in children and adolescents to that in adults, the CMSC considers that for optimal safety the recommendations for $\mathrm{sCr}$ determination and prevention of PC-AKI, which are predominantly based on studies in adults (aged 18+ years), should also be used for children and adolescents (Table 4).

\section{QUESTION 4: What are the patient- and procedure-related risk factors for developing PC-AKI and which patient populations have a higher risk for developing PC-AKI?}

\section{Patient-related risk factors}

Impaired renal function is the most important patient risk factor for PC-AKI. Many meta-analyses and systematic reviews of uncontrolled studies have identified a wealth of possible clinical risk factors for AKI in general such as old age, female gender, low BMI, classic cardiovascular and metabolic risk factors, malignancy, inflammation, bleeding, anaemia and hyperuricaemia [11, 12, 86-96]. However, uncontrolled studies cannot reliably differentiate baseline clinical risk factors from effects attributable specifically to CM. In a meta-analysis of controlled studies, no additional risk factors specific for CM were demonstrated [60] (Table 4). The effect of two or more risk factors is additive and increases the risk of PC-AKI.

\section{Procedure-related risk factors: CM type and dose}

A variety of risk factors have been related to the type of $\mathrm{CM}$ and the way it is administered.

Multiple meta-analyses have shown no evidence that isoosmolar CM (IOCM) are associated with a significantly lower rate of PC-AKI than non-ionic, low osmolar $\mathrm{CM}$ agents (LOCM) [97-100]. However, the risk of PC-AKI is increased when ionic, high-osmolar CM are used [101]. Repeated CM administration within a short interval $(48-72 \mathrm{~h})$ has been shown to increase the risk of PC-AKI [86] (Table 4).

Evidence about the influence of CM dose (CM volume $\mathrm{x}$ $\mathrm{CM}$ concentration) indicates dependence on the route of administration. There is insufficient evidence that dose is a problem with IV CM. However, for direct IA CM administration in coronary angiographic intervention it is advisable to keep the ratio of CM dose (in grams Iodine) to absolute eGFR (in ml/ min; corrected for body surface area) below $1.1[102,103]$ or to keep the ratio of $\mathrm{CM}$ volume (in $\mathrm{ml}$ ) to eGFR (in $\mathrm{ml} / \mathrm{min} /$ $1.73 \mathrm{~m}^{2}$ ) below 3.0 when using a $\mathrm{CM}$ concentration of 350 $\mathrm{mgl} / \mathrm{ml}[104,105]$ (Table 4). 


\section{Conclusion}

PC-AKI has been adopted as the best term to apply to renal function deterioration after intravascular $\mathrm{CM}$ administration because, unlike some of the older terms, it does not imply that $\mathrm{CM}$ is the cause. Stage 1 of the KDIGO classification of AKI is recommended as the change in renal function used to diagnose PC-AKI. The principal risk factor for PC-AKI is impaired renal function, and the recommended ways to measure this are by the CKD-EPI equation in adults and the Schwartz equation in children. In recent years, it has become apparent that the risk of true CI-AKI was overstated in the past. When properly corrected for the many other possible causes of AKI in patients with chronic kidney disease, the risk of CI-AKI when modern low osmolar CM are administered IV or IA is low. Repeated CM administration within a 24- to 48-h period increases the risk of CI-AKI. The evidence of a higher risk with IA than with IV CM administration is limited, but the CMSC nonetheless considers that the cut-off levels of eGFR used to indicate the need for prophylaxis before IA administration with first-pass renal exposure should be stricter, and that there should be a maximum volume of $\mathrm{CM}$ given intraarterially during any examination or procedure with first-pass renal exposure.

The recommendations made in this paper have been incorporated into the ESUR CMSC guidelines (see Table 4, Part 2).

Funding The authors state that this work has not received any funding.

\section{Compliance with ethical standards}

Guarantor The scientific guarantor of this publication is Prof. Henrik S. Thomsen.

Conflict of interest Aart van der Molen has received incidental payments for lectures and chairmanships at scientific meetings for contrast agent safety related issues (contrast agent reactions, Gd-retention) from GE, Bayer, Bracco and Guerbet

Fulvio Stacul has received lecture fees from Bracco and Guerbet

Olivier Clément has received lecture fees from Bracco and Guerbet

The other authors of this manuscript declare no relationships with any companies whose products and services may be related to the subject matter of this article.

Open Access This article is distributed under the terms of the Creative Commons Attribution 4.0 International License (http:// creativecommons.org/licenses/by/4.0/), which permits unrestricted use, distribution, and reproduction in any medium, provided you give appropriate credit to the original author(s) and the source, provide a link to the Creative Commons license, and indicate if changes were made.

\section{References}

1. Stacul F, van der Molen AJ, Reimer P, Contrast Media Safety Committee of European Society of Urogenital Radiology
(ESUR) et al (2011) Contrast induced nephropathy: updated ESUR Contrast Media Safety Committee guidelines. Eur Radiol 21:2527-2541

2. Morcos SK, Thomsen HS, Webb JA, Contrast Media Safety Committee of the European Society of Urogenital Radiology (ESUR) et al (2002) Dialysis and contrast media. Eur Radiol 12: 3026-3030

3. Contrast Media Safety Committee ESUR. Guidelines on Contrast Media v9. CMSC, 2014. Available via: http://www.esur-cm.org/ index.php/en/ Accessed: 14 December 2017

4. Gruberg L, Mintz GS, Mehran R et al (2000) The prognostic implications of further renal function deterioration within $48 \mathrm{~h}$ of interventional coronary procedures in patients with pre-existent chronic renal insufficiency. J Am Coll Cardiol 36:1542-1548

5. Gupta R, Gurm HS, Bhatt DL et al (2005) Renal failure after percutaneous coronary intervention is associated with high mortality. Catheter Cardiovasc Interv 64:442-448

6. James MT, Samuel SM, Manning MA et al (2013) Contrastinduced acute kidney injury and risk of adverse clinical outcomes after coronary angiography a systematic review and meta-analysis. Circ Cardiovasc Interv 6:37-43

7. Kooiman J, Seth M, Nallamothu BK et al (2015) Association between acute kidney injury and in-hospital mortality in patients undergoing percutaneous coronary interventions. Circ Cardiovasc Interv 8:e002212

8. Mitchell AM, Kline JA, Jones AE et al (2015) Major adverse events one year after acute kidney injury after contrast-enhanced computed tomography. Ann Emerg Med 66:267-274.e4

9. Rihal CS, Textor SC, Grill DE et al (2002) Incidence and prognostic importance of acute renal failure after percutaneous coronary intervention. Circulation 105:2259-2264

10. Rudnick M, Feldman H (2008) Contrast-induced nephropathy: what are the true clinical consequences? Clin J Am Soc Nephrol 3:263-272

11. Kooiman J, Pasha SM, Zondag W et al (2012) Meta-analysis: serum creatinine changes following contrast enhanced CT imaging. Eur J Radiol 81:2554-2561

12. Moos SI, van Vemde DN, Stoker J et al (2013) Contrast induced nephropathy in patients undergoing intravenous (IV) contrast enhanced computed tomography (CECT) and the relationship with risk factors: a meta-analysis. Eur J Radiol 82:e387-e399

13. Solomon R (2008) Contrast-induced acute kidney injury: is there a risk after intravenous contrast? Clin J Am Soc Nephrol 3:1242-1243

14. Dong M, Jiao Z, Liu T et al (2012) Effect of administration route on the renal safety of contrast agents: a meta-analysis of randomized controled trials. J Nephrol 25:290-301. https://www. radiologen.nl/secties/nvvr/documenten/richtlijn-veilig-gebruikvancontrastmiddelen-deel-1-full-english

15. Keeley EC (1998) Grines CL (1998) Scraping of aortic debris by coronary guiding catheters: a prospective evaluation of 1,000 cases. J Am Coll Cardiol 32:1861-1865

16. Wichmann JL, Katzberg RW, Litwin SE et al (2015) Contrastinduced nephropathy. Circulation 132:1931-1936

17. Newhouse JH, Kho D, Rao QA et al (2008) Frequency of serum creatinine changes in the absence of iodinated contrast material: implications for studies of contrast nephrotoxicity. AJR Am J Roentgenol 191:376-382

18. Bruce RJ, Djamali A, Shinki K et al (2009) Background fluctuation of kidney function versus contrast-induced nephrotoxicity. AJR American Journal of Roentgenology 192:711-718

19. Brouwers M, Kho ME, Browman GP, on behalf of the AGREE Next Steps Consortium et al (2010) AGREE II: Advancing guideline development, reporting and evaluation in healthcare. Can Med Assoc J 182:E839-E842 
20. Guyatt GH, Oxman AD, Kunz R et al (2011) GRADE guidelines: 2. Framing the question and deciding on important outcomes. J Clin Epidemiol 64:395-400

21. OCEBM Levels of Evidence Working Group. The Oxford 2011 Levels of Evidence. Oxford Centre for Evidence-Based Medicine. Available via: http://www.cebm.net/index.aspx?o=5653 Accessed 14 December 2017

22. Bellomo R, Ronco C, Kellum JA, Mehta RL, Palevsky P, Acute Dialysis Quality Initiative workgroup (2004) Acute renal failure definition, outcome measures, animal models, fluid therapy and information technology needs: the Second International Consensus Conference of the Acute Dialysis Quality Initiative (ADQI) Group. Crit Care 8:R204-R212

23. Levey AS, Eckardt KU, Tsukamoto Y et al (2005) Definition and classification of chronic kidney disease: a position statement from Kidney Disease: Improving Global Outcomes (KDIGO). Kidney Int 67:2089-2100

24. Mehta RL, Kellum JA, Shah SV et al (2007) Acute Kidney Injury Network. Acute Kidney Injury Network: report of an initiative to improve outcomes in acute kidney injury. Crit Care 11:R31

25. ACR Committee on Drugs and Contrast Media. ACR Manual on Contrast Media, v10.3. American College of Radiology, 2017 Available via: https://www.acr.org/-/media/ACR/Files/ClinicalResources/Contrast_Media.pdf Accessed: 14 December 2017

26. Kellum JA, Lameire N (2013) Diagnosis, evaluation, and management of acute kidney injury: a KDIGO summary (Part 1). Crit Care 17:204

27. Kidney Disease: Improving Global Outcomes (KDIGO) Acute Kidney Injury Work Group (2012) KDIGO Clinical Practice Guideline for Acute Kidney Injury. Kidney Int Suppl 2:1-138

28. Morcos SK, Thomsen HS, Webb JA (1999) Contrast-mediainduced nephrotoxicity: a consensus report. Contrast Media Safety Committee, European Society of Urogenital Radiology (ESUR). Eur Radiol 9:1602-1613

29. Pyxaras SA, Zhang Y, Wolf A, Schmitz T, Naber CK (2015) Effect of varying definitions of contrast-induced acute kidney injury and left ventricular ejection fraction on one-year mortality in patients having transcatheter aortic valve implantation. Am J Cardiol 116:426-430

30. Slocum NK, Grossman PM, Moscucci M et al (2012) The changing definition of contrast-induced nephropathy and its clinical implications: insights from the Blue Cross Blue Shield of Michigan Cardiovascular Consortium (BMC2). Am Heart J 163:829-834

31. Weisbord SD, Mor MK, Resnick AL, Hartwig KC, Palevsky PM, Fine MJ (2008) Incidence and outcomes of contrast-induced AKI following computed tomography. Clin J Am Soc Nephrol 3:1274-1281

32. Budano C, Levis M, D'Amico M et al (2011) Impact of contrastinduced acute kidney injury definition on clinical outcomes. Am Heart J 161:963-971

33. Azzouz M, Rømsing J, Thomsen HS (2014) Fluctuations in eGFR in relation to unenhanced and enhanced MRI and CT outpatients. Eur J Radiol 83:886-892

34. Thomsen HS, Morcos SK (2009) Risk of iodinated contrast material-induced nephropathy with intravenous administration. Eur Radiol 19:891-897

35. Lakhal K, Ehrmann S, Chaari A et al (2011) Acute Kidney Injury Network definition of contrast-induced nephropathy in the critically ill: incidence and outcome. J Crit Care 26:593-599

36. Garfinkle MA, Stewart S, Basi R (2015) Incidence of CT contrast agent-induced nephropathy: toward a more accurate estimation. AJR Am J Roentgenol 204:1146-1151

37. Thomas ME, Blaine C, Dawnay A et al (2015) The definition of acute kidney injury and its use in practice. Kidney Int 87:62-73

38. Fliser D, Laville M, Covic A et al (2012) A European Renal Best Practice (ERBP) position statement on the Kidney Disease Improving Global Outcomes (KDIGO) clinical practice guidelines on acute kidney injury: part 1: definitions, conservative management and contrast-induced nephropathy. Nephrol Dial Transplant 27:4263-4272

39. Levey AS, Bosch JP, Lewis JB, Greene T, Rogers N, Roth D (1999) A more accurate method to estimate glomerular filtration rate from serum creatinine: a new prediction equation. Modification of Diet in Renal Disease Study Group. Ann Intern Med 130:461-470

40. Levey AS, Coresh J, Greene T et al (2007) Expressing the MDRD study equation for estimating GFR with standardized serum creatinine values. Clin Chem 53:766-772

41. Levey AS, Coresh J, Greene T, Chronic Kidney Disease Epidemiology Collaboration et al (2006) Using standardized serum creatinine values in the modification of diet in renal disease study equation for estimating glomerular filtration rate. Ann Intern Med 145:247-254. https://www.acr.org/-/media/ACR/ Files/Clinical-Resources/Contrast Media.pdf

42. Levey AS, Stevens LA, Schmid CH, CKD-EPI (Chronic Kidney Disease Epidemiology Collaboration) et al (2009) A new equation to estimate glomerular filtration rate. Ann Intern Med 150:604-612

43. Stevens LA, Li S, Kurella Tamura M et al (2011) Comparison of the CKD Epidemiology Collaboration (CKD-EPI) and Modification of Diet in Renal Disease (MDRD) study equations: risk factors for and complications of CKD and mortality in the Kidney Early Evaluation Program (KEEP). Am J Kidney Dis 57:S9-S16

44. Björk J, Jones I, Nyman U, Sjostrom P (2012) Validation of the Lund-Malmo, Chronic Kidney Disease Epidemiology (CKD-EPI) and Modification of Diet in Renal Disease (MDRD) equations to estimate glomerular filtration rate in a large Swedish clinical population. Scand J Urol Nephrol 46:212-222

45. Schäffner ES, Ebert N, Delanaye P et al (2012) Two novel equations to estimate kidney function in persons aged 70 years or older. Ann Intern Med 157:471-481

46. Pottel H, Hoste L, Dubourg L et al (2016) An estimated glomerular filtration rate equation for the full age spectrum. Nephrol Dial Transplant 31:798-806

47. Florkowski CM, Chew-Harris JSC (2011) Methods of Estimating GFR - Different Equations Including CKD-EPI. Clin Biochem Rev 32:75-79

48. Delanaye P, Ebert N (2012) Assessment of kidney function: estimating GFR in children. Nat Rev Nephrol 8:503-504

49. Schwartz GJ, Haycock GB, Edelmann CM Jr, Spitzer A (1976) A simple estimate of glomerular filtration rate in children derived from body length and plasma creatinine. Pediatrics 58:259-263

50. Schwartz GJ, Munoz A, Schneider MF et al (2009) New equations to estimate GFR in children with CKD. J Am Soc Nephrol 20:629-637

51. Schwartz GJ, Schneider MF, Maier PS et al (2012) Improved equations estimating GFR in children with chronic kidney disease using an immunonephelometric determination of cystatin C. Kidney Int 82:445-453

52. Martinez Lomakin F, Tobar C (2014) Accuracy of point-of-care serum creatinine devices for detecting patients at risk of contrast-induced nephropathy: a critical overview. Crit Rev Clin Lab Sci 51:332-343

53. Rao QA, Newhouse JH (2006) Risk of nephropathy after intravenous administration of contrast material: a critical literature analysis. Radiology 239:392-397

54. Katzberg RW, Newhouse JH (2010) Intravenous contrast medium-induced nephrotoxicity: is the medical risk really as great as we have come to believe? Radiology 256:21-28

55. Stratta P, Bozzola C, Quaglia M (2012) Pitfall in nephrology: contrast nephropathy has to be differentiated from renal damage due to atheroembolic disease. J Nephrol 25:282-289

56. McDonald RJ, McDonald JS, Newhouse JH, Davenport MS (2015) Controversies in contrast material-induced acute kidney injury: closing in on the truth? Radiology 277:627-632 
57. Nyman U, Aspelin P, Jakobsen J, Bjork J (2015) Controversies in contrast material-induced acute kidney injury: Propensity Score matching of patients with different dose/absolute glomerular filtration rate ratios. Radiology 277:633-637

58. Ricos C, Iglesias N, Garcia-Lario JV et al (2007) Within-subject biological variation in disease: collated data and clinical consequences. Ann Clin Biochem 44:343-352

59. Wilhelm-Leen E, Montez-Rath ME, Chertow G (2017) Estimating the risk of radiocontrast-associated nephropathy. J Am Soc Nephrol 28:653-659

60. McDonald JS, McDonald RJ, Comin J etal(2013) Frequency of acute kidney injury following intravenous contrast medium administration: a systematic review and meta-analysis. Radiology 267:119-128

61. Schünemann HJ, Tugwell P, Reeves BC etal (2013) Non-randomized studies as a source of complementary, sequential or replacement evidence for randomized controlled trials in systematic reviews on the effects of interventions. Res Synth Methods 4:49-62

62. Davenport MS, Khalatbari S, Dillman JR, Cohan RH, Caoili EM, Ellis JH (2013) Contrast material-induced nephrotoxicity and intravenous low-osmolality iodinated contrast material. Radiology 267:94-105

63. Davenport MS, Khalatbari S, Cohan RH, Dillman JR, Myles JD, Ellis JH (2013) Contrast material-induced nephrotoxicity and intravenous low-osmolality iodinated contrast material: risk stratification by using estimated glomerular filtration rate. Radiology 268:719-728

64. McDonald RJ, McDonald JS, Bida JP et al (2013) Intravenous contrast material-induced nephropathy: causal or coincident phenomenon? Radiology 267:106-118

65. McDonald JS, McDonald RJ, Carter RE, Katzberg RW, Kallmes DF, Williamson EE (2014) Risk of intravenous contrast materialmediated acute kidney injury: a propensity score-matched study stratified by baseline-estimated glomerular filtration rate. Radiology 271:65-73

66. McDonald JS, McDonald RJ, Lieske JC et al (2015) Risk of acute kidney injury, dialysis, and mortality in patients with chronic kidney disease after intravenous contrast material exposure. Mayo Clin Proc 90:1046-1053

67. Karlsberg RP, Dohad SY, Sheng R (2011) Iodixanol peripheral computed tomographic angiography study investigator panel. Contrast medium acute kidney injury: comparison of intravenous and intra-arterial administration of iodinated contrast medium. J Vasc Intervent Radiol 22:1159-1165

68. Kooiman J, Le Haen PA, Gezgin G et al (2013) Contrast-induced acute kidney injury and clinical outcomes after intra-arterial and intravenous contrast administration: risk comparison adjusted for patient characteristics by design. Am Heart J 165:793-799

69. McDonald JS, Leake CB, McDonald RJ et al (2016) Acute kidney injury after intravenous versus intra-arterial contrast material administration in a paired cohort. Invest Radiol 51:804-809

70. Tong GE, Kumar S, Chong KC et al (2016) Risk of contrastinduced nephropathy for patients receiving intravenous vs. intraarterial iodixanol administration. Abdom Radiol 41:91-99

71. From AM, Bartholmai BJ, Williams AW, Cha SS, McDonald FS (2008) Mortality associated with nephropathy after radiographic contrast exposure. Mayo Clin Proc 83:1095-1100

72. Nyman U, Almén T, Jacobsson B, Aspelin P (2012) Are intravenous injections of contrast media really less nephrotoxic than intra-arterial injections? Eur Radiol 22:1366-1371

73. Prasad A, Ortiz-Lopez C, Khan A, Levin D, Kaye DM (2016) Acute kidney injury following peripheral angiography and endovascular therapy: a systematic review of the literature. Catheter Cardiovasc Interv 88:264-273

74. Aubry P, Brillet G, Catella L, Schmidt A, Bénard S (2016) Outcomes, risk factors and health burden of contrast-induced acute kidney injury: an observational study of one million hospitalizations with image-guided cardiovascular procedures. BMC Nephrol 17:167
75. Haider M, Yessayan L, Venkat KK, Goggins M, Patel A, Karthikeyan V (2015) Incidence of contrast-induced nephropathy in kidney transplant recipients. Transplant Proc 47:379-383

76. Fananapazir G, Troppmann C, Corwin MT, Bent CK, Vu CT, Lamba R (2016) Incidence of contrast-induced nephropathy after renal graft catheter arteriography using iodine-based contrast medium. AJR Am J Roentgenol 206:783-786

77. Fananapazir G, Troppmann C, Corwin MT, Nikpour AM, Naderi S, Lamba R (2016) Incidences of acute kidney injury, dialysis, and graft loss following intravenous administration of low-osmolality iodinated contrast in patients with kidney transplants. Abdom Radiol 41:2182-2186

78. Haveman JW, Gansevoort RT, Bongaerts AH, Nijsten MW (2006) Low incidence of nephropathy in surgical ICU patients receiving intravenous contrast: a retrospective analysis. Intensive Care Med 32:1199-1205

79. Hoste EA, Doom S, De Waele J et al (2011) Epidemiology of contrast-associated acute kidney injury in ICU patients: a retrospective cohort analysis. Intensive Care Med 37:1921-1931

80. Cely CM, Schein RM, Quartin AA (2012) Risk of contrast induced nephropathy in the critically ill: a prospective, case matched study. Crit Care 16:R67

81. Ehrmann S, Badin J, Savath L et al (2013) Acute kidney injury in the critically ill: is iodinated contrast medium really harmful? Crit Care Med 41:1017-1026

82. McDonald JS, McDonald RJ, Williamson EE, Kallmes DF, Kashani K (2017) Post-contrast acute kidney injury in intensive care unit patients: a propensity score-adjusted study. Intensive Care Med 43:774-784

83. Senthilnathan S, Gauvreau K, Marshall AC, Lock JE, Bergersen L (2009) Contrast administration in pediatric cardiac catheterization: dose and adverse events. Catheter Cardiovasc Interv 73:814-820

84. Huggins N, Nugent A, Modem V et al (2014) Incidence of acute kidney injury following cardiac catheterization prior to cardiopulmonary bypass in children. Catheter Cardiovasc Interv 84:615-619

85. Cantais A, Hammouda Z, Mory O et al (2016) Incidence of contrast-induced acute kidney injury in a pediatric setting: a cohort study. Pediatr Nephrol 31:1355-1362

86. Balemans CE, Reichert LJ, van Schelven BI, van den Brand JA, Wetzels JF (2012) Epidemiology of contrast material-induced nephropathy in the era of hydration. Radiology 263:706-713

87. Kanbay M, Solak Y, Afsar B et al (2017) Serum uric acid and risk for acute kidney injury following contrast: an evaluation of epidemiology, clinical trials, and potential mechanisms. Angiology 68:132-144

88. Kiski D, Stepper W, Breithardt G, Reinecke H (2010) Impact of female gender on frequency of contrast medium-induced nephropathy: post hoc analysis of dialysis versus diuresis trial. J Womens Health 19:1363-1368

89. Kwasa EA, Vinayak S, Armstrong R (2014) The role of inflammation in contrast-induced nephropathy. Br J Radiol 87:20130738

90. Medalion B, Cohen H, Assali A et al (2010) The effect of cardiac angiography timing, contrast media dose, and preoperative renal function on acute renal failure after coronary artery bypass grafting. J Thorac Cardiovasc Surg 139:1539-1544

91. Ohno Y, Maekawa Y, Miyata H et al (2013) Impact of periprocedural bleeding on incidence of contrast-induced acute kidney injury in patients treated with percutaneous coronary intervention. J Am Coll Cardiol 62:1260-1266

92. Pannu N, Wiebe N, Tonelli M (2006) Prophylaxis strategies for contrast-induced nephropathy. JAMA 295:2765-2779

93. Song W, Zhang T, Pu J, Shen L, He B (2014) Incidence and risk of developing contrast-induced acute kidney injury following intravascularcontrastadministration in elderly patients. Clin Interv Aging 9:85-93

94. Toprak O, Cirit M (2006) Risk factors for contrast-induced nephropathy. Kidney Blood Press Res 29:84-93 
95. Yang JQ, Ran P, Chen JY et al (2014) Development of contrastinduced acute kidney injury after elective contrast media exposure in patients with type 2 diabetes mellitus: effect of albuminuria. PLoS One 9:e106454

96. Zuo T, Jiang L, Mao S, Liu X, Yin X, Guo L (2016) Hyperuricemia and contrast-induced acute kidney injury: A systematic review and meta-analysis. Int J Cardiol 224:286-294

97. McDonald JS, McDonald RJ, Williamson EE, Kallmes DF (2017) Is intravenous administration of iodixanol associated with increased risk of acute kidney injury, dialysis, or mortality? a Propensity Scoreadjusted study. Radiology. 285: 414-424

98. Heinrich MC, Häberle L, Müller V, Bautz W, Uder M (2009) Nephrotoxicity of iso-osmolar iodixanol compared with nonionic low-osmolar contrast media: meta-analysis of randomized controlled trials. Radiology 250:68-86

99. From AM, Al Badarin FJ, McDonald FS, Bartholmai BJ, Cha SS, Rihal CS (2010) Iodixanol versus low-osmolar contrast media for prevention of contrast induced nephropathy: meta-analysis of randomized, controlled trials. Circ Cardiovase Interv 3:351-358

100. Eng J, Wilson RF, Subramaniam RM et al (2016) Comparative effect of contrast media type on the incidence of contrast-induced nephropathy: a systematic review and meta-analysis. Ann Intern Med 164:417-424

101. Barrett BJ, Carlisle EJ (1993) Meta-analysis of the relative nephrotoxicity of high- and low-osmolality iodinated contrast media. Radiology 188:171-178

102. Gurm HS, Dixon SR, Smith DE, BMC2 (Blue Cross Blue Shield of Michigan Cardiovascular Consortium) Registry et al (2011) Renal function-based contrast dosing to define safe limits of radiographic contrast media in patients undergoing percutaneous coronary interventions. J Am Coll Cardiol 58:907-914

103. Kooiman J, Seth M, Share D, Dixon S, Gurm HS (2014) The association between contrast dose and renal complications post-PCI across the continuum of procedural estimated risk. PLoS One 9:e90233

104. Nyman U, Björk J, Aspelin P, Marenzi G (2008) Contrast medium dose-to-GFR ratio: a measure of systemic exposure to predict contrast-induced nephropathy after percutaneous coronary intervention. Acta Radiol 49:658-667

105. Nyman U (2016) Contrast dose, estimated GFR and techniques to reduce contrast dose in PCI - time to consider some basic principles! J Invas Cardiol 28:E126-E127

\section{Affiliations}

\section{Aart J. van der Molen ${ }^{1} \cdot$ Peter Reimer $^{2}$ • Ilona A. Dekkers ${ }^{1} \cdot$ Georg Bongartz $^{3}$ - Marie-France Bellin ${ }^{4}$. Michele Bertolotto $^{5}$. Olivier Clement ${ }^{6} \cdot$ Gertraud Heinz-Peer $^{7} \cdot$ Fulvio Stacul $^{8}$ • Judith A. W. Webb ${ }^{9}$. Henrik S. Thomsen ${ }^{10}$}

1 Department of Radiology, C2-S, Leiden University Medical Center, Albinusdreef 2, NL-2333 ZA Leiden, The Netherlands

2 Institute for Diagnostic and Interventional Radiology, Klinikum Karlsruhe, Academic Teaching Hospital of the University of Freiburg, Moltkestraße 90, D-76133 Karlsruhe, Germany

3 Department of Diagnostic Radiology, University Hospitals of Basel, Petersgaben 4, CH-4033 Basel, Switzerland

4 Service Central de Radiologie Hôpital Paul Brousse 14, av. P.-V.Couturier, F-94807 Villejuif, France

5 Department of Radiology, University of Trieste, Strada di Fiume 447, I-34149 Trieste, Italy
6 Department of Radiology, Assistance Publique-Hôpitaux de Paris, Hôpital Européen Georges Pompidou, 20, rue Leblanc, Paris Cedex 15, F-71015 Paris, France

7 Department of Radiology, Zentralinstitut für medizinische Radiologie, Diagnostik und Intervention, Landesklinikum St. Pölten, Propst Führer-Straße 4, AT-3100 St. Pölten, Austria

8 S.C. Radiologia Ospedale Maggiore, Piazza Ospitale 1 I-34129 Trieste, Italy

9 Department of Radiology, St. Bartholomew's Hospital, University of London, West Smithfield, London EC1A 7BE, UK

10 Department of Diagnostic Radiology 54E2, Copenhagen University Hospital Herlev, Herlev Ringvej 75, DK-2730 Herlev, Denmark 